\title{
Heart rate variability in healthy subjects: effect of age and the derivation of normal ranges for tests of autonomic function
}

\author{
IAIN A D O'BRIEN, PAUL O'HARE, ROGER J M CORRALL \\ From the Department of Medicine, Bristol Royal Infirmary, Bristol
}

SUMMARY The diagnosis of autonomic neuropathy frequently depends on results of tests which elicit reflex changes in heart rate. Few well-documented normal ranges are available for these tests. The present study was designed to investigate the effect of age upon heart rate variability at rest and in response to a single deep breath, the Valsalva manoeuvre, and standing. A computerised method of measurement of $R-R$ interval variation was used to study heart rate responses in 310 healthy subjects aged $18-85$ years.

Heart rate variation during each procedure showed a skewed distribution and a statistically significant negative correlation with age. Normal ranges (90\% and $95 \%$ confidence limits) for subjects aged 20-75 years were calculated for heart rate difference $(\max -\min )$ and ratio $(\mathrm{max} / \mathrm{min}$ ) and standard deviation (SD). Heart rate responses were less than the 95 th centile in at least one of the four procedures in $39(12.6 \%)$ out of the 310 subjects, and were below this limit in two or more tests in five $(1.6 \%)$ subjects. In view of the decline in heart rate variation with increasing age, normal ranges for tests of autonomic function must be related to the age of the subject.

In recent years several simple, non-invasive tests of autonomic function have been described. ${ }^{12}$ These tests are based on measurement of reflex changes in heart rate in response to standardised stimuli, such as the Valsalva manoeuvre, ${ }^{3}$ single ${ }^{4}$ or repeated deep breaths, ${ }^{5}$ passive tilting, or standing. ${ }^{67}$ More complex procedures, such as lower body negative pressure $^{8}$ and injection of pressor agents, ${ }^{9}$ provide additional information about autonomic control of the cardiovascular system but are not suitable for routine clinical use.

Assessment of heart rate variability in subjects of all ages is, however, complicated by changes that occur in the autonomic nervous system with advancing age. ${ }^{10}$ These changes include a gradual increase in basal and stimulated plasma noradrenaline concentrations, ${ }^{11}$ altered adrenoceptor function, ${ }^{12}$ and diminished responsiveness to adrenergic agonists and antagonists. ${ }^{13}$ The heart rate response to the

Requests for reprints to $\operatorname{Dr} I$ A D O'Brien, Department of Medicine, Bristol Royal Infirmary, Bristol BS2 8HW.

Accepted for publication 17 December 1985
Valsalva manoeuvre and deep breathing tests declines with age in normal subjects. ${ }^{3.14}$ Consequently normal ranges for such procedures that quote a single limit for all ages, ${ }^{15}$ with or without a borderline range, are inappropriate and will result in errors in diagnosis, particularly in the elderly.

The present study was undertaken to evaluate the effect of age upon heart rate variation in a large group of healthy subjects, and thus to establish confidence limits for the heart rate response to standard tests of autonomic function.

\section{Subjects and methods}

\section{SUBJECTS}

A total of 310 healthy normal subjects, 147 males and 163 females, were studied. The age range was 18-85 years (mean (SD) 48 (17)); in each decade from 20 to 70 years of age there was a minimum of 50 subjects, approximately $50 \%$ males and $50 \%$ females (Table 1). Most of those aged less than 65 were factory employees, a few were hospital staff and healthy outpatients attending the physiotherapy department. Those aged 65-85 years were volun- 
Table 1 Age and sex distribution of subjects

\begin{tabular}{llllllc}
\hline Sex & $18-29 y r$ & $30-39 y r$ & $40-49 y r$ & $50-59 y r$ & $60-69 y r$ & $70-85 y r$ \\
\hline$M$ & 32 & 31 & 23 & 29 & 24 & 8 \\
F & 23 & 27 & 29 & 27 & 29 & 28 \\
Total $(\%)$ & $55(17 \cdot 7)$ & $58(18 \cdot 7)$ & $52(16 \cdot 8)$ & $56(18 \cdot 1)$ & $53(17 \cdot 1)$ & $36(11 \cdot 6)$ \\
\hline
\end{tabular}

teers from day centres for the elderly in Bristol. Diabetic patients were excluded, as were those with cardiac failure, angina, cerebrovascular disease, and those taking drugs known to affect heart rate. None of the subjects had glycosuria.

\section{METHODS}

Changes in heart rate were measured with an instantaneous cardiac ratemeter (Lectromed type 4522 model A) interfaced with a microcomputer (Commodore $4008 \mathrm{~N}$ ). Details of the method have been reported elsewhere. ${ }^{10}$ The computer was programmed to record heart rate in either beats per minute or milliseconds per beat. A signal generated by an $R$ wave simulator set at a rate of $60 \mathrm{~min}^{-1}$ was measured with $100 \%$ accuracy over a period of two minutes.

Heart rate was measured continuously during four procedures in each subject as follows: (a) quiet supine rest for $60 \mathrm{~s}$; $(b)$ a single deep breath-the subject was asked to inhale deeply over $5 \mathrm{~s}$ and then to exhale over $5 \mathrm{~s}$; (c) Valsalva manoeuvre-the subject was asked to maintain a pressure of $40 \mathrm{~mm} \mathrm{Hg}$ for $15 \mathrm{~s}$ by means of forced expiration into a mouthpiece connected to a sphygmomanometer, the subject then lay quietly while heart rate was recorded for a further $45 \mathrm{~s} ;(d)$ standing for $60 \mathrm{~s}$ (in this case the recording was started immediately the subject was erect). These are referred to hereafter as resting, inspiration, Valsalva, and standing. Subjects were supine or semirecumbent during $(a)-(c)$. In addition blood pressure over the brachial artery was measured with a standard sphygmomanometer before and after the subject had stood for $60 \mathrm{~s}$. All studies were performed by a single investigator (IAD O'B).

The following data were recorded from each test: maximum, minimum, mean, and SD of heart rate in beats $/ \mathrm{min}$. The values of the 15 th and 30 th beats after standing were noted also. ${ }^{11}$ From these results, we derived the following indices of heart rate variation: heart rate difference $(\max -\min )$, heart rate ratio $(\mathrm{max} / \mathrm{min})$, heart rate $S D$, and $30: 15$ ratio.

\section{STATISTICAL ANALYSIS}

The influence of age and other variables on heart rate variation was examined by non-parametric techniques. Multiple correlation analysis was used to study the relation of age, resting heart rate, and blood pressure to heart rate variation. The difference in heart rate variability between males and females was compared by unpaired $t$ tests. To derive confidence limits for indices of heart rate variation it was necessary to use a transformation technique because of the skewed distribution of results and the non-linear relation with age. Thus the original data were transformed to normality by the method of Box and Cox, in which a general power transformation is used to convert the original data to normality. ${ }^{12}$ Confidence limits were then calculated and the data were transformed back.

Table 2 The relative contribution of age, systolic blood pressure (BP), and basal heart rate to heart rate variation at rest and in response to the Valsalva manoeuvre, a single deep breath, and standing (values given are those of the change in $R^{2}$ at each stage in multiple correlation analysis)

\begin{tabular}{|c|c|c|c|}
\hline Index & Age & Systolic BP & Mean heart rate \\
\hline \multicolumn{4}{|c|}{ Heart rate difference: } \\
\hline Resting & $23.0 \%$ & - & $0.2 \%$ \\
\hline Inspiration & $32.6 \%$ & - & - \\
\hline Valsalva & $20.5 \%$ & $0.8 \%$ & $4.0 \%$ \\
\hline \multirow{2}{*}{\multicolumn{4}{|c|}{ Heart rate ratio: }} \\
\hline & & & \\
\hline Resting & $23.4 \%$ & - & $2 \cdot 7 \%$ \\
\hline Inspiration & $29 \cdot 2 \%$ & - & $3.3 \%$ \\
\hline Valsalva & $19 \cdot 5 \%$ & $1.6 \%$ & - \\
\hline Standing & $29 \cdot 1 \%$ & - & $1 \cdot 3 \%$ \\
\hline \multicolumn{4}{|l|}{ Heart rate SD: } \\
\hline Resting. & $15 \cdot 4 \%$ & - & - \\
\hline Inspiration & $30 \cdot 5 \%$ & $\overline{1.10}$ & $\overline{0.80}$ \\
\hline $\begin{array}{l}\text { Valsalva } \\
\text { Standing }\end{array}$ & $\begin{array}{l}17 \cdot 9 \% \\
33.1 \%\end{array}$ & $1 \cdot 1 \%$ & - \\
\hline
\end{tabular}




\section{Results}

The correlation coefficient of heart rate indices with age ranged from $-0.45(p<0.001)$ for resting heart rate SD to $-0.60(p<0.001)$ for standing heart rate difference. Heart rate difference and SD were independent of resting heart rate in all tests, whereas heart rate ratio showed a weak correlation with resting heart rate in all procedures except for the Valsalva manoeuvre. There was also a significant negative correlation of heart rate variability with supine systolic blood pressure; however, this was due almost entirely to the dependence of blood pressure on age $(r=0.59, p<0.001)$. Multiple correlation analysis showed that age accounted for $15-33 \%$ of
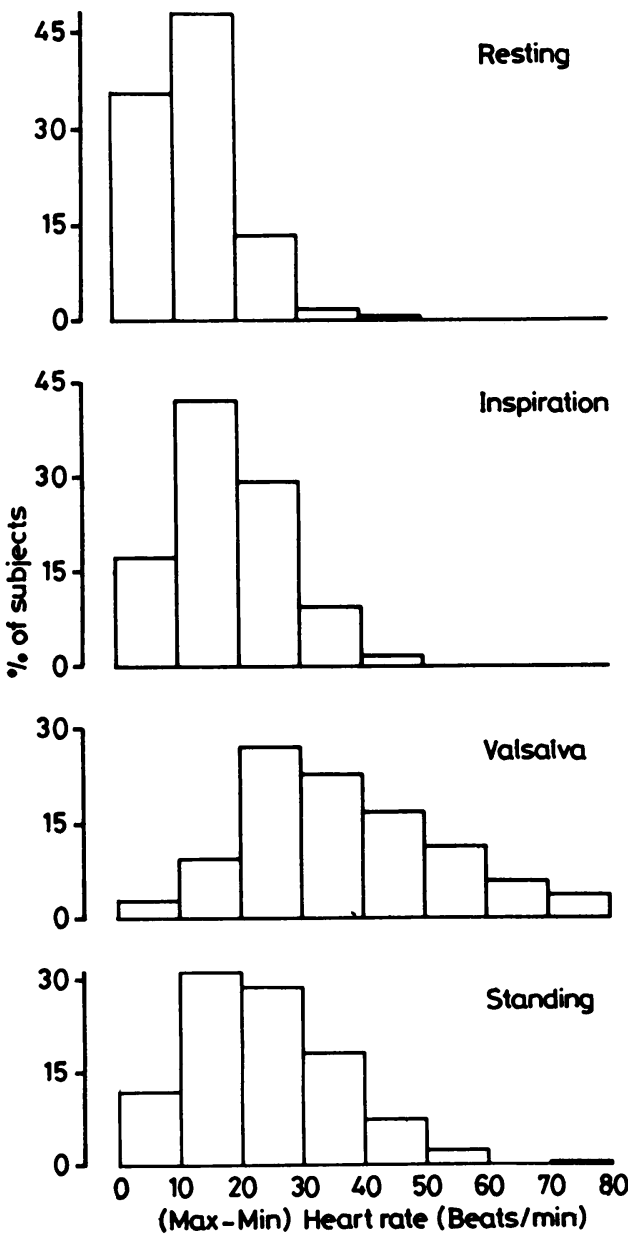

Fig. 1 Heart rate differences in normal subjects measured at rest, during a single deep breath, Valsalva manoeuvre, and standing $(n=310)$. variation in heart rate responsiveness in normal subjects, and that less than $4 \%$ was attributable to basal heart rate or blood pressure (Table 2).

Comparison of heart rate results between males and females was confined to subjects aged $<70$ years because of a preponderance of females above this age. Heart rate variability was generally less in women than in men; however, with the exception of heart rate ratio at rest $(p=0.004)$, the difference did not reach statistical significance. Therefore, results from both sexes were analysed together.

The relative change in heart rate in response to the various procedures was Valsalva $>$ standing $>$ inspiration $>$ resting. All indices of heart rate variability showed unimodal, positively skewed distributions. For example, Fig. 1 shows data for heart rate difference. Figure 2 shows the asymmetrical scatter of Valsalva ratios. It also illustrates the nonlinear decline in heart rate responsiveness with increasing age and the $90 \%$ and $95 \%$ confidence limits derived by the transformation technique described above. The values of $90 \%$ and $95 \%$ confidence limits for heart rate difference, ratio, and $\mathrm{SD}$ in response to each procedure are given in Table 3.

Individual subjects rarely had results outside these limits in more than one test. Heart rate responses were less than the 95th centile in at least one of the four procedures in $39(12.6 \%)$ out of 310 subjects. In the entire group heart rate difference results were outside the lower $95 \%$ confidence limit in two or more of the four tests in only two out of the 310 subjects $(0.6 \%)$. Similarly, only three subjects $(0.9 \%)$ had two or more abnormal heart rate ratios or SDs.

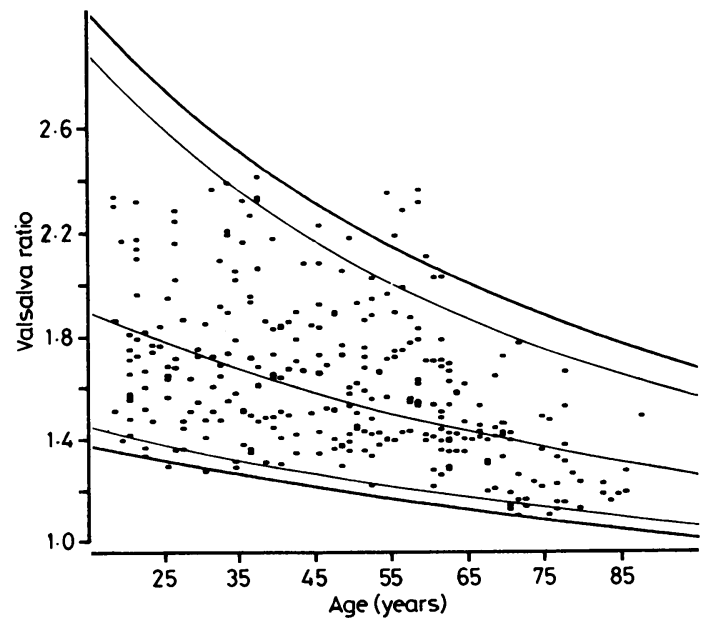

Fig. 2 Age-related decline in the Valsalva ratio in normal subjects $(n=310)$ and $90 \%$ and $95 \%$ confidence limits. 
Table 3 Normal ranges for heart rate responses in normal subjects aged 20-75 years. Values given are (a) the lower 95\% and (b) the lower $90 \%$ confidence limits

\begin{tabular}{|c|c|c|c|c|c|c|c|c|c|c|c|c|}
\hline & $20 y r$ & $25 y r$ & $30 y r$ & $35 y r$ & $40 y r$ & $45 y r$ & $50 y r$ & $55 y r$ & $60 y r$ & $65 y r$ & $70 y r$ & $75 y r$ \\
\hline \multicolumn{13}{|c|}{ Heart rate difference: } \\
\hline $\begin{array}{c}\text { Resting } \\
\text { (a) }\end{array}$ & 7 & 7 & 6 & 6 & 5 & 5 & 5 & 4 & 4 & 4 & 3 & 3 \\
\hline (b) & 9 & 8 & 7 & 7 & 6 & 6 & 5 & 5 & 5 & 4 & 4 & 4 \\
\hline \multicolumn{13}{|l|}{ Inspiration } \\
\hline (b) & 13 & 12 & 11 & 10 & 9 & $\begin{array}{l}6 \\
8\end{array}$ & $\begin{array}{l}5 \\
7\end{array}$ & $\begin{array}{l}5 \\
6\end{array}$ & $\begin{array}{l}4 \\
5\end{array}$ & $\begin{array}{l}3 \\
4\end{array}$ & $\begin{array}{l}3 \\
4\end{array}$ & ${ }_{3}^{2}$ \\
\hline \multicolumn{13}{|l|}{ Valsalva } \\
\hline $\begin{array}{l}\text { (a) } \\
\text { (b) }\end{array}$ & $\begin{array}{l}22 \\
25\end{array}$ & $\begin{array}{l}20 \\
23\end{array}$ & $\begin{array}{l}19 \\
22\end{array}$ & $\begin{array}{l}17 \\
20\end{array}$ & $\begin{array}{l}16 \\
19\end{array}$ & $\begin{array}{l}15 \\
17\end{array}$ & $\begin{array}{l}13 \\
16\end{array}$ & $\begin{array}{l}12 \\
15\end{array}$ & $\begin{array}{l}11 \\
13\end{array}$ & $\begin{array}{l}19 \\
12\end{array}$ & 99 & $\begin{array}{r}8 \\
10\end{array}$ \\
\hline \multicolumn{13}{|l|}{ Standing } \\
\hline $\begin{array}{l}\text { (a) } \\
\text { (b) }\end{array}$ & $\begin{array}{l}15 \\
17\end{array}$ & $\begin{array}{l}13 \\
16\end{array}$ & $\begin{array}{l}12 \\
14\end{array}$ & $\begin{array}{l}11 \\
13\end{array}$ & $\begin{array}{r}9 \\
11\end{array}$ & $\begin{array}{r}8 \\
10\end{array}$ & $\begin{array}{l}7 \\
9\end{array}$ & $\begin{array}{l}6 \\
8\end{array}$ & $\begin{array}{l}5 \\
7\end{array}$ & $\begin{array}{l}5 \\
6\end{array}$ & $\begin{array}{l}4 \\
5\end{array}$ & $\begin{array}{l}3 \\
4\end{array}$ \\
\hline \multicolumn{13}{|c|}{$\begin{array}{l}\text { Heart rate ratio: } \\
\text { Resting }\end{array}$} \\
\hline (a) & $1 \cdot 12$ & $1 \cdot 11$ & $1 \cdot 10$ & 1.09 & 1.08 & 1.07 & 1.06 & 1.05 & 1.04 & 1.04 & 1.03 & 1.02 \\
\hline \multirow{2}{*}{\multicolumn{13}{|c|}{$\begin{array}{l}\text { Inspiration } \\
(\mathbf{a})\end{array}$}} \\
\hline & $\begin{array}{l}1.17 \\
1.20\end{array}$ & $\begin{array}{l}1 \cdot 15 \\
1 \cdot 18\end{array}$ & $\begin{array}{l}1 \cdot 13 \\
1 \cdot 16\end{array}$ & $\begin{array}{l}1 \cdot 12 \\
1 \cdot 14\end{array}$ & $\begin{array}{l}1 \cdot 10 \\
1 \cdot 13\end{array}$ & $\begin{array}{l}1.08 \\
1 \cdot 11\end{array}$ & $\begin{array}{l}1.07 \\
1.09\end{array}$ & $\begin{array}{l}1.06 \\
1.08\end{array}$ & $\begin{array}{l}1.04 \\
1.06\end{array}$ & $\begin{array}{l}1.03 \\
1.05\end{array}$ & $\begin{array}{l}1.02 \\
1.04\end{array}$ & $\begin{array}{l}1.00 \\
1.02\end{array}$ \\
\hline \multicolumn{13}{|l|}{$\begin{array}{l}\text { (b) } \\
\text { Valsalva }\end{array}$} \\
\hline $\begin{array}{c}\text { (a) } \\
\text { (b) } \\
\text { Standing }\end{array}$ & $\begin{array}{l}1.35 \\
1.41\end{array}$ & $\begin{array}{l}1.32 \\
1.38\end{array}$ & $\begin{array}{l}1.30 \\
1.35\end{array}$ & $\begin{array}{l}1.27 \\
1.32\end{array}$ & $\begin{array}{l}1.24 \\
1.29\end{array}$ & $\begin{array}{l}1.24 \\
1.27\end{array}$ & $\begin{array}{l}1.20 \\
1.24\end{array}$ & $\begin{array}{l}1.17 \\
1.22\end{array}$ & $\begin{array}{l}1.15 \\
1.19\end{array}$ & $\begin{array}{l}1.13 \\
1.17\end{array}$ & $\begin{array}{l}1 \cdot 11 \\
1.15\end{array}$ & $\begin{array}{l}1.09 \\
1.13\end{array}$ \\
\hline \multicolumn{2}{|l|}{ Standing } & $1 \cdot 17$ & $1 \cdot 15$ & $1 \cdot 13$ & $1 \cdot 12$ & $1 \cdot 10$ & 1.08 & 1.06 & 1.05 & 1.03 & 1.02 & 1.01 \\
\hline $\begin{array}{c}\text { (b) } \\
\text { Heart rate } S D:\end{array}$ & 1.23 & 1.21 & $1 \cdot 19$ & $1 \cdot 16$ & $1 \cdot 14$ & $1 \cdot 13$ & $1 \cdot 11$ & 1.09 & 1.07 & 1.06 & 1.04 & 1.03 \\
\hline \multicolumn{13}{|l|}{$\begin{array}{l}\text { Heart rate SD: } \\
\text { Resting }\end{array}$} \\
\hline $\begin{array}{l}\text { (a) } \\
\text { (b) }\end{array}$ & 1.6 & 1.5 & 1.4 & $1 \cdot 3$ & 1.3 & $1 \cdot 2$ & $1 \cdot 1$ & $1 \cdot 1$ & 1.0 & $1 \cdot 0$ & 0.9 & 0.9 \\
\hline \\
\hline $\begin{array}{l}\text { (a) } \\
\text { (b) }\end{array}$ & $\begin{array}{l}3 \cdot 6 \\
4 \cdot 3\end{array}$ & $\begin{array}{l}3.2 \\
3.9\end{array}$ & $\begin{array}{l}2.9 \\
3.5\end{array}$ & $\begin{array}{l}2 \cdot 5 \\
3 \cdot 1\end{array}$ & $\begin{array}{l}2 \cdot 2 \\
2.7\end{array}$ & $\begin{array}{l}1.9 \\
2.4\end{array}$ & $\begin{array}{l}1 \cdot 6 \\
2 \cdot 1\end{array}$ & $\begin{array}{l}1.4 \\
1.8\end{array}$ & $\begin{array}{l}1.2 \\
1.5\end{array}$ & $\begin{array}{l}0.9 \\
1.3\end{array}$ & $\begin{array}{l}0.8 \\
1 \cdot 1\end{array}$ & $\begin{array}{l}0.6 \\
0.9\end{array}$ \\
\hline \\
\hline $\begin{array}{c}\text { (a) } \\
\text { (b) } \\
\text { Standing }\end{array}$ & $\begin{array}{l}6.0 \\
7.2\end{array}$ & $\begin{array}{l}5.6 \\
6.6\end{array}$ & $\begin{array}{l}5.1 \\
6 \cdot 1\end{array}$ & $\begin{array}{l}4 \cdot 7 \\
5 \cdot 6\end{array}$ & $\begin{array}{l}4 \cdot 3 \\
5 \cdot 1\end{array}$ & $\begin{array}{l}3 \cdot 9 \\
4 \cdot 7\end{array}$ & $\begin{array}{l}3 \cdot 5 \\
4 \cdot 3\end{array}$ & $\begin{array}{l}3.2 \\
3.9\end{array}$ & $\begin{array}{l}2.9 \\
3.6\end{array}$ & $\begin{array}{l}2 \cdot 6 \\
3 \cdot 2\end{array}$ & $\begin{array}{l}2 \cdot 3 \\
2 \cdot 9\end{array}$ & $\begin{array}{l}2 \cdot 1 \\
2 \cdot 6\end{array}$ \\
\hline \multirow{2}{*}{$\begin{array}{l}\text { Standing } \\
\text { (a) } \\
\text { (b) }\end{array}$} & $\begin{array}{l}3.6 \\
4.3\end{array}$ & $\begin{array}{l}3.3 \\
3.9\end{array}-1$ & $\begin{array}{r}2.9 \\
3.5\end{array}$ & 2.6 & 2.3 & $2 \cdot 0$ & $1 \cdot 7$ & 1.5 & 1.3 & $\begin{array}{l}1.1 \\
1.4\end{array}$ & 0.9 & 0.8 \\
\hline & 4 & 9 & 3 & דיכ & 24 & $2 \cdot 4$ & $2 \cdot 1$ & 1.9 & 1.6 & 1.4 & 1.2 & 1.0 \\
\hline
\end{tabular}

The timing of maximum and minimum heart rates on standing was determined in 219 subjects: maximum heart rate occurred within $10 \mathrm{~s}$ in $77 \%$. In contrast, the timing of minimum rate showed a much wider scatter. The 30:15 ratio was compared with $(\mathrm{max} / \mathrm{min})$ heart rate ratio on standing in 294 subjects. There was a significant correlation between both measurements $(r=0.45, p<0.001)$. The 30:15 ratio was $<1.00$ in $43 \%$, however, and thus this derived index consistently underestimated the true $\max / \min$ ratio.

As expected, supine systolic blood pressure was positively correlated with age $(r=0.59, p<0.001)$. The difference between supine and standing systolic blood pressure was independent of age $(r=-0.01, p$ NS). Four subjects, all of whom were aged 60-65 years, had a fall in systolic pressure on standing of 20-25 $\mathrm{mm} \mathrm{Hg}$.

The reproducibility of the heart rate response to each procedure was assessed in a separate study of six healthy male subjects aged 20-35 years, each of whom was studied on five separate occasions over three days. Heart rate ratios were found to have a lower coefficient of variation than heart rate differences or SDs (Table 4).

\section{Discussion}

Variation in heart rate, whether at rest or in response to a stimulus, is mediated by the combined effects of cardiac vagal and sympathetic nerves acting upon the sinoatrial node. The aim of simple clinical tests, such as were used in the present study, in which the

Table 4 Coefficients of variation (mean (range)) of heart rate measurements in six normal subjects

\begin{tabular}{llll}
\hline & Heart rate & \multicolumn{1}{l}{$S D$} \\
\cline { 2 - 3 } & Difference & Ratio & \\
\hline Resting & $29 \%(18-44 \%)$ & $7 \%(6-9 \%)$ & $25 \%(12-34 \%)$ \\
Inspiration & $16 \%(7-28 \%)$ & $6 \%(2-9 \%)$ & $21 \%(13-34 \%)$ \\
Valsalva & $17 \%(4-29 \%)$ & $9 \%(4-16 \%)$ & $21 \%(2-27 \%)$ \\
Standing & $26 \%(12-31 \%)$ & $9 \%(4-16 \%)$ & $24 \%(10-41 \%)$ \\
\hline
\end{tabular}


chronotropic response to standardised manoeuvres is measured, is to investigate the integrity of these autonomic control mechanisms. Assessment of heart rate variability is, however, complicated by changes in the autonomic nervous system that occur with advancing age. ${ }^{13}$ These functional changes include a gradual increase in basal and stimulated plasma noradrenaline concentrations, ${ }^{14}$ altered adrenoceptor function, ${ }^{15}$ and diminished responsiveness to adrenergic agonists and antagonists. ${ }^{16}$ The results of the present study demonstrate that age is an important determinant of heart rate variability in normal subjects. Thus, unless allowance is made for the physiological effects of aging, diminished heart rate variability in older subjects may be attributed incorrectly to disease.

In this study of more than $\mathbf{3 0 0}$ healthy subjects, care was taken to ensure an even distribution of age and sex. It was necessary to use a transformation technique to analyse the data because the distribution of results was skewed, and the deline in heart rate responsiveness with age was non-linear. Alternative transformation methods were used by Smith and Wieling to derive normal ranges for heart rate variation at rest ${ }^{17}$ and in response to deep breathing, ${ }^{1718}$ the Valsalva manoeuvre, ${ }^{19}$ and standing. ${ }^{18}$ We have obtained slightly lower limits, probably due to the larger number and more uniform age distribution of our subjects. Many previous studies of cardiovascular autonomic function tests, particularly those of diabetic autonomic neuropathy, have been of small groups of subjects or narrow age ranges or both. ${ }^{112021}$ In some instances recommended normal limits have not taken account of observed reductions in heart rate variability in older subjects ${ }^{32223}$; in others normal ranges have been defined "arbitrarily". ${ }^{24}$

Sinus arrhythmia is enhanced during $\beta$ adrenergic blockade $^{25}$ and is abolished by atropine. ${ }^{5}$ Thus, although the precise mechanisms responsible for sinus arrhythmia are not fully understood, the efferent pathway is via cardiac vagal fibres. Respiratory-induced changes in heart rate are reduced in the elderly. ${ }^{417182627}$ This may be due to altered vagal activity, since the chronotropic response to atropine is also reduced in older subjects. ${ }^{28}$ Bennett et al, in a comparative study of cardiac autonomic function tests, found that resting $R-R$ interval SD correlated negatively with mean heart rate, and that $R-R$ interval SD was not useful in detecting subjects with impaired heart rate responsiveness. ${ }^{9}$ In the present study, heart rate variability during quiet and deep breathing was independent of mean heart rate, and it was possible to derive age-related limits for resting heart rate variation. In studying the response to deep breath- ing we used a single breath rather than repeated breaths, since the magnitude of the change in rate is often greater during the first breath and diminishes thereafter. ${ }^{9}$ Ewing and Clarke have recommended a normal range of $>15$ beats $/ \mathrm{min}$ for heart rate difference during deep breathing, with $11-14$ as borderline and $<11$ as abnormal. ${ }^{29}$ Our results indicate that these limits are not applicable to subjects of all ages; our results (Table 3 ) are, however, similar to the limits obtained by Mackay $e t$ al and Sundkvist $e t$ $a l$ in subjects aged $<50$ years. ${ }^{22} 30$

The Valsalva manoeuvre elicits a complex series of haemodynamic events that result in activation of sympathetic and parasympathetic neurones. It has been suggested that the cardiac response to Valsalva should be represented by the increase or decrease in rate relative to the initial heart rate. ${ }^{31}$ Both these indices, however, correlate closely with the Valsalva ratio, and the latter has the advantage of being independent of basal heart rate. In a study of 200 normal subjects by Levin, the Valsalva ratio decreased with age and $96 \%$ had ratios $>1 \cdot 5 .^{3}$ The normal ranges that we have calculated for the Valsalva ratio are lower than 1.5 at all ages, and are generally higher than the limit of 1.10 set by Ewing and Clarke. ${ }^{29}$ Our results are, however, similar to the range found by Dyrberg et al in subjects aged $30-48 .^{20}$

The increase in heart rate on standing diminishes with age ${ }^{26}$ (Table 3). The ratio of the R-R intervals of the 30th and 15th beats after standing, the 30:15 ratio, has been proposed as an index of the reflex heart rate response to standing. ${ }^{11}$ The mechanisms underlying the immediate heart rate response to standing are complex, ${ }^{7}$ and the present data indicate that these changes in rate are not accurately represented by the 30:15 ratio because of the high frequency of false positive results. Others have also found the 30:15 ratio to be unhelpful and to underestimate the true $\max / \min$ ratio. ${ }^{1832}$

Postural hypotension is a relatively common finding in the elderly. Caird et al found that $16 \%$ of 494 people aged more than 65 have a systolic fall $>20 \mathrm{~mm} \mathrm{Hg}$ on standing. ${ }^{33}$ This degree of postural hypotension was less common among our subjects, occurring in only $4.5 \%$ of those aged 60 or more. This may have been due to differences in the study populations, since contributory factors were identified in $40 \%$ of Caird's subjects with postural hypotension and such individuals would have been excluded from the present study.

It is a contentious issue whether the response to tests of autonomic function should be expressed as the difference or the ratio of the induced change in heart rate (or $\mathbf{R}-\mathbf{R}$ interval). Although the relation between these two indices is linear, the slope is dependent on basal heart rate (Fig. 3). Thus, if a 


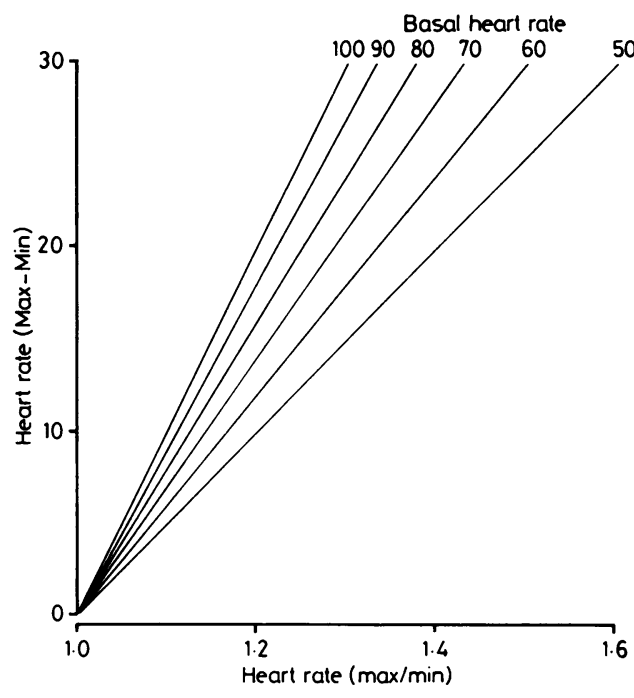

Fig. 3 The effect of basal heart rate upon the relation between heart rate difference ( $\max -\min$ ) and heart rate ratio ( $\mathrm{max} / \mathrm{min})$.

particular test induces a heart rate difference of 20 beats/min the corresponding heart rate ratio will be 1.33 for a basal heart rate of $60,1.20$ for a basal rate of 100 , and $1 \cdot 17$ for a basal rate of 120 . Furthermore, it is not known whether a change in heart rate from 60 to 80 is comparable physiologically to a change in rate from 100 to 120 . Since there is no consensus on which index should be used to express the heart rate response, we have presented all our data after all three methods of analysis. The expression of heart rate data as either ratios or differences may also be relevant to the diagnosis of diabetic autonomic neuropathy. It is well documented that heart rates are, in general, faster in diabetics than in nondiabetics. $^{25920}$ Consequently, autonomic dysfunction may be diagnosed more frequently if ratios rather than differences are used.

It is important to recognise that a diagnosis of autonomic neuropathy cannot be substantiated on the basis of the results from a single test. ${ }^{29}$ Among the reasons for this are the variability of results in healthy subjects, the different physiological basis of the various tests, and, in the case of disease states, the patchy distribution of lesions within the autonomic nervous system. Using a combination of four simple procedures we have shown that $<2 \%$ of a normal population will have more than one abnormal test result. We suggest, therefore, that abnormal autonomic control of heart rate can be diagnosed with confidence using these tests with age-related normal ranges.
We thank Dr R J Hunt, Department of Mathematics, Statistics and Operational Research, University of Exeter, for assistance and statistical advice.

\section{References}

1 Anonymous. Diagnosis of autonomic neuropathy. $\mathrm{Br}$ Med f 1978; ii: 910-1.

2 Ewing DJ. Cardiovascular reflexes and autonomic neuropathy. Clin Sci Mol Med 1978; 55: 321-7.

3 Levin AB. A simple test of cardiac function based upon the heart rate changes induced by the Valsalva maneuver. Am f Cardiol 1966; 18: 90-9.

4 Smith SA. Reduced sinus arrhythmia in diabetic autonomic neuropathy: diagnostic value of an age-related normal range. $\mathrm{Br} \mathrm{Med} F$ 1982; 285: 1599-601.

5 Wheeler T, Watkins PJ. Cardiac denervation in diabetics. $\mathrm{Br}$ Med f 1973; iv: 584-6.

6 Ewing DJ, Hume L, Campbell IW, Murray A, Neilson JMM, Clarke BF. Autonomic mechanisms in the initial heart rate response to standing. $\mathcal{F}$ Appl Physiol 1980; 49: 809-14.

7 Borst C, Wieling W, van Brederode JFM, Hond A, de Rijk LG, Dunning AJ. Mechanisms of initial heart rate response to postural change. Am $\mathcal{F}$ Physiol 1982; 243: H676-81.

8 Bennett T, Hosking DJ, Hampton JR. Cardiovascular responses to graded reductions of central blood volume in normal subjects and in patients with diabetes mellitus. Clin Sci 1980; 58: 193-200.

9 Bennett T, Farquhar IK, Hosking DJ, Hampton JR. Assessment of methods for estimating autonomic nervous control of the heart in patients with diabetes mellitus. Diabetes 1978; 27: 1157-74.

10 O'Brien IAD, Corrall RJM. Cardiovascular autonomic function testing: an automated method for measuring heart rate variation. Diabetic Medicine 1985; 2: 143-4.

11 Ewing DJ, Campbell IW, Murray A, Neilson JMM, Clarke BF. Immediate heart rate response to standing: simple test for autonomic neuropathy in diabetes. $\mathrm{Br}$ Med f 1978; i: 145-7.

12 Box GEP, Cox DR. An analysis of transformations. $\mathcal{F}$ Roy Statisc Soc 1964; 26: 211-52.

13 Rowe JW, Troen BR. Sympathetic nervous system and aging in man. Endocr Rev 1980; 1: 167-79.

14 Ziegler MG, Lake CR, Kopin IJ. Plasma noradrenaline increases with age. Nature 1976; 261: 333-4.

15 Kelly J, O'Malley K. Adrenoceptor function and ageing. Clin Sci 1984; 66: 509-15.

16 Vestal RE, Wood AJJ, Shand DG. Reduced $\beta$-adrenoceptor sensitivity in the elderly. Clin Pharmacol Ther 1979; 26: 181-6.

17 Smith SE, Smith SA. Heart rate variability in healthy subjects measured with a bedside computer-based technique. Clin Sci 1981; 61: 379-83.

18 Wieling W, van Brederode JFM, de Rijk LG, Dunning AJ. Reflex control of heart rate in normal subjects in relation to age: a data base for cardiac vagal neuropathy. Diabetologia 1982; 22: 163-6. 
19 Smith SA. Diagnostic value of the Valsalva ratio reduction in diabetic autonomic neuropathy: use of an agerelated normal range. Diabetic Medicine 1984; 1: 295-7.

20 Dyrberg T, Benn J, Christiansen JS, Hilsted J, Nerup J. Prevalence of diabetic autonomic neuropathy measured by simple bedside tests. Diabetologia 1981; 20: 190-4.

21 Hilsted J, Jensen SB. A simple test for autonomic neuropathy in juvenile diabetics. Acta Med Scand 1979; 205: 385-7.

22 Mackay JD, Page M McB, Cambridge J, Watkins PJ. Diabetic autonomic neuropathy. The diagnostic value of heart rate monitoring. Diabetologie 1980; 18: 471-8.

23 Masaoka S, Lev-Ran A, Hill LR, Vakil G, Hon EHG. Heart rate variability in diabetes: relationship to age and duration of the disease. Diabetes Care 1985; 8: 64-8.

24 Ewing DJ, Campbell IW, Burt AA, Clarke BF. Vascular reflexes in diabetic autonomic neuropathy. Lancet 1973; ii: $1354-6$.

25 Coker R, Koziell A, Oliver C, Smith SE. Does the sympathetic nervous system influence sinus arrhythmia in man? Evidence from combined autonomic blockade. $\mathcal{F}$ Physiol (Lond) 1984; 356: 459-64.
26 Collins KJ, Exton-Smith AN, James MH, Oliver DJ. Functional changes in autonomic nervous responses with ageing. Age Ageing 1980; 9: 17-24.

27 Waddington JL, McCulloch MJ, Sambrooks JE. Resting heart rate variability in man declines with age. Experientia 1979; 35: 1197-8.

28 Dauchot P, Gravenstein JS. Effects of atropine on the electro-cardiogram in different age groups. Clin Pharmacol Ther 1970; 12: 274-80.

29 Ewing DJ, Clarke BF. Diagnosis and management of diabetic autonomic neuropathy. $\mathrm{Br} \mathrm{Med} \mathcal{F}$ 1982; 285: 916-8.

30 Sundkvist G, Almer L-O, Lilja B. Respiratory influence on heart rate in diabetes mellitus. $\mathrm{Br}$ Med $\mathcal{f}$ 1979; i: 924-5.

31 Nathanielsz PW, Ross EJ. Abnormal response to Valsalva máneuver in diabetics. Diabetes $1967 ; 16: 462-5$.

32 Baldwa VS, Ewing DJ. Heart rate response to Valsalva manoeuvre. Reproducibility in normals, and relation to variation in resting heart rate in diabetics. $\mathrm{Br}$ Heart $\mathcal{f}$ 1977; 39: 641-4.

33 Caird FI, Andrews GR, Kennedy RD. Effect of posture on blood pressure in the elderly. Br Heart $\mathcal{F} 1973$; 35: $527-30$. 